\title{
Routine Screening for Cervical Cancer
}

\author{
Alassane Traoré ${ }^{*}$, Aphou Sallé Koné ${ }^{2}$, Sima Mamadou ${ }^{3}$, Amadou Bocoum4, \\ Mamadou Bakary Coulibaly¹, Koninba Diabaté ${ }^{2}$, Adama Diakitée, \\ Kanté Ibrahim³ ${ }^{3}$ Seydou Mariko1, Idrissa Mama Diarra²

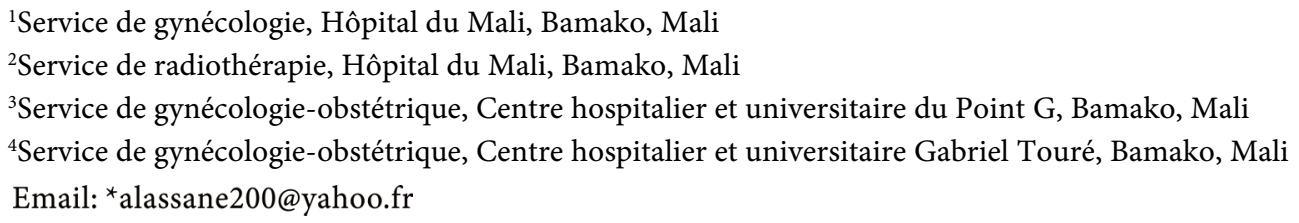

How to cite this paper: Traoré, A., Koné, A.S., Mamadou, S., Bocoum, A., Coulibaly, M.B., Diabaté, K., Diakité, A., Ibrahim, K., Mariko, S. and Diarra, I.M. (2021) Routine Screening for Cervical Cancer. Open Journal of Obstetrics and Gynecology, 11, 922-928. https://doi.org/10.4236/ojog.2021.117087

Received: May 14, 2021

Accepted: July 25, 2021

Published: July 28, 2021

Copyright $\odot 2021$ by author(s) and Scientific Research Publishing Inc. This work is licensed under the Creative Commons Attribution International License (CC BY 4.0).

http://creativecommons.org/licenses/by/4.0/

\begin{abstract}
Objective: To describe the screening for uterine cancer by visual methods. Method: We conducted a prospective and descriptive study over a period of 12 months from January to December 2020. Direct observation of providers and interview of patients were performed for data collection. Results: Out of 3400 patients, 1024 were enrolled for the study, or $30.11 \%$. The average age of the patients was 41 years with the extremes of 17 to 87 years. Women aged 40 to 45 were the most represented with 58.78\%, $(\mathrm{n}=602)$. Housewives $85.83 \%(\mathrm{n}=$ $879)$, they had a primary education level in $71.09 \%$ of cases $(n=728)$, the vast majority were married $92.28 \%(\mathrm{n}=945)$. Multiparous represented $58.78 \%(\mathrm{n}=$ 602) of the sample, nulliparous $18.26 \%(\mathrm{n}=187)$, women living in rural areas $30.17 \%(\mathrm{n}=309)$, in urban areas $69.82 \%(\mathrm{n}=715)$. The test was positive in 43 patients (4.19\%) but squamocylindrical junction was not visible in $17 \%$ of cases. The preparation of acetic acid and lugol: good preparation in $100 \%$ of cases; the conditions of use are not respected in $27 \%$ for acetic acid and $38 \%$ for lugol. Conclusion: Routine screening for cervical cancer (SCC) by visual methods is essential to decrease the incidence of invasive cervical cancer.
\end{abstract}

\section{Keywords}

Cervical Cancer, Screening, Hôpital du Mali

\section{Introduction}

Cancer of the cervix is the third most common cancer in women worldwide [1].

About 500,000 new cases are recorded each year with advanced stages including 83,000 cases in developed countries and over 400,000 (80\%) cases in developing countries. That is regrettable for a preventable pathology [2]. 
According to data from the Malian Cancer Registry, cervical cancer ranks first among female cancers with a frequency of $26.60 \%$ and an incidence of 35.1 per 100,000 inhabitants [3]. In developing countries, in Africa and in Mali, the diagnosis of cervical cancer is in most cases performed at late stages or even incurable, which makes the therapeutic results disappointing and the cost of treatment high [4]. The delay for a specialized consultation is multifactorial, we can note the lack of knowledge about cancer, the care of traditional therapists, the absence of screening, the accessibility to modern care.

In developed countries, the implementation of a cervico-uterine smear (CUS) screening program has been accompanied by a reduction in the incidence and mortality from cervical cancer, allowing the treatment of precancerous lesions and early management of cancers [4]. Today, primary prevention is organized around sex education for young people from high school onwards, the prevention of genital infections, and vaccination against the human papillomavirus (HPV). Cervical cancer being the consequence of chronic infection with the HPV, vaccination is an important bulwark in the fight against cervical cancer that African countries are struggling to put in place.

Invasive cervical cancers (ICC) are currently the tenth leading cause of cancer in women in France with 3068 new cases in 2005. Its incidence has been declining for nearly three decades, which is the case in most industrialized countries (3387 cases in 2000, the eighth leading cause of female cancer). In Europe, thanks to the generalization of screening, the incidence is gradually decreasing (30,000 new cases per year) but remains responsible for 13,500 deaths per year [5].

In France, the practice of cervical smears has contributed to the marked reduction in the incidence and mortality of cervical cancer. French recommendations, confirmed very recently by the High Authority of Health (HAH), recommend screening by cervical smear in all women who have had sexual intercourse from the age of 25 and up to 65 years. Two smears are taken one year apart and then repeated every three years if they are normal [6].

In Mali, the detection of cancer is done largely at advanced stages, metastatic making the costs of treatment very high, the care trying for the patient and his family. Supportive care structures are lacking and the management of patients with advanced cervical cancer is becoming a challenge. Yet cervical cancer is preventable, it is accessible to screening with little means and by all health providers who have received training. SCC by visual methods, visual inspection by acetic acid (IVA) and visual inspection with lugol (IVL) are an alternative to screening by cervicovaginal smear. It is organized in Mali since the 2000s through daily consultations in community health structures and hospitals but also through mass screening organized by non-governmental organizations (NGOs) and learned societies.

A high rate of participation in screening must be obtained to ensure the expected benefits of screening. Also the quality of reception and communication are elements that can improve attendance at cervical cancer screening units and 
therefore reduce its incidence.

The objectives of this study were to describe the screening for uterine cancer by visual methods and to assess the performance of cervical cancer screening in the gynecology department of Hôpital du Mali.

\section{Methodology}

We carried out a prospective and cross-sectional study over a period of 12 months from January to December 2020. Patient recruitment was exhaustive and concerned women who had already done sexual activity and who joined the study through an informed consent. Pregnant women and those in post-partum period for three months were excluded. We observed health care providers during the reception and in the process of cervical cancer screening (preparation of solutions, placement of speculum, application of solutions). We interviewed the patients on their feelings and satisfaction with the screening.

The evaluation focused on the quality of the reception, the preparation of IVA and AVL, the visualization of SCJ by the providers, the reading of the screening result, patient satisfaction.

\section{Results}

We collected 1024 patients out of 3400 patients seen in the gynecology department, or $30.11 \%$. The average age of the patients was 41 years with extremes of 17 to 87 years. Women aged 40 to 45 were the most represented $58.78 \%$ ( $\mathrm{n}=$ 602). The socio-demographic characteristics of the patients were as follows, housewives $85.83 \%(\mathrm{n}=879)$ with a primary education level $71.09 \%(\mathrm{n}=728)$, the vast majority were married $92.28 \%(\mathrm{n}=945)$. Multiparous represented $58.78 \%(\mathrm{n}=602)$ of the sample, nulliparous $18.26 \%(\mathrm{n}=187)$, women living in rural areas $30.17 \%(n=309)$, in urban areas $69.82 \%(n=715)$.

The quality of the reception: it was satisfactory in 63\%, unsatisfactory in $37 \%$

The preparation of acetic acid and lugol: good preparation in 100\% of cases, the conditions of use are not respected in 27\% for IVA and 38\% for IVL.

Visualization of SCJ: It was not visible in $17 \%$ of cases, the speculum was not suitable in 78 patients, or $7.61 \%$ of cases.

Screening results: Of 1,024 screened patients 43 were positive $4.19 \%$ and 981 women had a negative test $95.81 \%$.

Patient satisfaction: the satisfaction rate for women was $93.06 \%(n=953)$.

\section{Discussion}

Screening cervical cancer is a routine activity in the department of gynecology of Hôpital du Mali. It is carried out every working day by qualified providers such as gynecologists obstetricians, midwives and nurses.

\subsection{Screening Unit Attendance}

The success of the cervical cancer prevention policy depends on the number 
of people attending the screening unit. In countries with limited resources where vaccination against the HPV virus is poorly done, or the literacy rate is low, emphasis should be put on screening which is an important pillar of primary prevention of cervical cancer. In addition, in Mali, early marriage being frequent, which is a significant factor in cervical cancer, in the absence of large-scale vaccination of the population, screening must be required. At Hôpital du Mali, communication for screening is performed by midwives in the waiting and hospital rooms. Also, all women who consult for a gynecological problem are advised and referred to the screening unit. Among the women consulted in the gynecology department during the study period, 30\% were screened for cervical cancer. This rate is satisfactory because a large part of the patients at the time of the examination had already been screened in other structures during the current year.

In the study of Erik Bernard [7] the effective participation rate of patients in screening was high, with almost 9 out of 10 women reporting an up-to-date smear.

The age of patients at first screening can be critical in preventing cervical cancer. Based on the natural history of this cancer which will lead to the transformation of normal cells into cancerous cells over a period of 10 to 15 years, we must be able to determine the period of cell transformation, to perform as much screening as possible during this period and to provide appropriate management of metaplasias. The expected benefits of screening depend, first of all, on the number of subjects detectable in the preclinical phase and the duration of this phase: the longer this phase, the higher the probability of detection. Knowing the duration of the detectable preclinical phase makes it possible to propose the age at the start of screening and the periodicity between two tests as opportune as possible [8]. The frequency of HPV infection plays an important role in the development of precancerous lesions. The virus is easily transmitted through sexual contact. Condom use only reduces the risk of infection by 70\% [9]. It then penetrates into the basal cells of the genital epithelium, either through micro-abrasions of the mucosa, or due to the quasi-physiological exposure of these basal cells at the level of the squamocylindrical junction of the uterus. This infection is common in sexually active adolescent girls and young adults [10].

In our study, the most represented age group, 40 to 45 , is a real encouraging reason. Regardless of the age at the start of screening, the preclinical phase and early cervical cancer will be identified most often in this age group. This early detection will allow timely management and prevent the development of invasive cancer, the management of which is heavy with deleterious economic and social consequences. In C. CHAN CHEE's study [11], women in the age group 40 - 49 were the most likely to report a smear in the past three years (Table 1).

\subsection{The Quality of the Reception in the Cervical Cancer Screening Unit}

In general, a good quality of reception motivates patients to attend health 
Table 1. Socio-demographic characteristics of patients.

\begin{tabular}{cccc}
\hline \multicolumn{2}{c}{ Characteristics } & Number & Percentage \\
\hline \multicolumn{2}{c}{ Housewives } & 879 & $85.83 \%$ \\
Level of primary education & 728 & $71.09 \%$ \\
\multicolumn{2}{c}{ Married women } & 945 & $92.28 \%$ \\
Parity & Multiparous & 602 & $58.78 \%$ \\
& Nulliparous & 187 & $18.26 \%$ \\
Residence & Rural & 309 & $30.17 \%$ \\
& Urban & 715 & $69.82 \%$ \\
\hline
\end{tabular}

services but also helps to fight against bad rumors which are likely to reduce the use of services. Reception must begin with the cleanliness of the premises, and the provision of seating for patients. Then good communication while reassuring users, other elements such as confidentiality, discretion and waiting time must be taken into account in the reception. The poor quality of reception during the study was related to the lack of seating places for patients, the waiting time so long, and the cleanliness of the screening room. Also the high number of learners in the room may discourage some patients.

\subsection{Preparation and Use of Acetic Acid and Lugol}

Preparation is done daily by providers for acetic acid. The rules are respected by making a dosage at $5 \%$, stored in a transparent container. For its use a quantity is poured into a container which is not closed, this dose can be used for four to five women except women do not follow each other very closely. The solution can be left for 30 to 40 minutes in the open air, under these conditions it loses its qualities which can lead to a bad result.

The IVL is already prepared at the pharmacy and stored in a dark container, protected from light. Its use is done in the same way like IVA, a portion is poured into an uncovered container, exposed to free air and light can deteriorate its quality.

\subsection{Visualization of the SCJ}

This junction represents the starting point of cervical cancer. Its vision is a necessity during screening to avoid false results. In some patients, especially in menopause, the SCJ can rise up into the cervical canal, making it difficult to visualize. These patients should be prepared specifically for screening, in some cases the use of vaginal prostaglandin to soften the cervix and promote separation of the two labia of the cervix. Also, the correct installation of the patient and the choice of a suitable speculum facilitate access to the SCJ.

In $17 \%$ of patients the SCJ was not visible because of anatomical and physiological changes but also because the available specula were not suitable for different women. The size of the speculum used must be in proportion to the body 
of the patient.

\subsection{Screening Results}

Of 1024 screened patients 43 were positive or $4.19 \%$ and 981 women had a negative test or $95.81 \%$. Good management of patients tested positive will certainly prevent invasive cancer in these cases. Health policies must be oriented towards the prevention and early management of pathologies, in particular cancers accessible to screening. Edith M. in Gabon [12] found out $36.89 \%$ of positive cases, Bakali G. in Morocco [13] 30\% of positivity in her study. This large difference in positivity in these studies compared to ours is partly accounted for by the use of the colposcopy for better assessment of lesions and by the target population for screening (Table 2).

Table 2. Performance for IVA/IVL screening.

\begin{tabular}{cc} 
Performances & Percentage \\
\hline Sensibility & $73.68 \%$ \\
specificity & $97.95 \%$ \\
Positive predictive value (PPV) & $80 \%$ \\
Negative predictive value (NPV) & $97.10 \%$ \\
\hline
\end{tabular}

\subsection{Patient Satisfaction}

The satisfaction rate of women was $93.06 \%(\mathrm{n}=953)$, reporting a negative result was the most important in patients' satisfaction compared with other aspects. An improvement in the other conditions of reception can increase the attendance rate of the screening unit, it is especially confidentiality by reducing the number of learners in the room, the cleanliness of the room, and the availability of health providers for screening.

\section{Conclusion}

In the absence of vaccination against the human papillomavirus, screening for cervical cancer remains an important pillar in the fight against this cancer. Strengthening the technical platform with a colposcopy can improve the quality of results.

\section{Limitations}

We did not perform a test for HPV virus that would allow better interpretation and adequate management of the lesions.

The results of anatomical and pathological examinations were not available to assess the sensitivity and specificity of the screening methods.

\section{Conflicts of Interest}

The authors declare no conflicts of interest regarding the publication of this paper. 


\section{References}

[1] Ferley, J., Shin, H.R., Bray, F., Forman, D., Mathers, C. and Parkin, D.M. (2010) GLOBOCAN 2008, Cancer Incidence and Mortality Worldwide: IARC Cancer Base Number 10 [Internet]. http://globocan.iarc.fr

[2] Delvenne, P., Jacobs, N., Dean and Kridelka, K. (2003) Cervical Cancer Screening in Belgium: Update in 2003. Rev. med. Cork, 58, 316-318.

[3] Bayo, S., Parkin, D.M., Koumare, A.K., Diallo, A.N., Ba, T., Soumaré, S. and Sangaré, S. (1990) Cancer in Mali, 1987-1988. International Journal of Cancer, 45, 679-684. https://doi.org/10.1002/ijc.2910450418

[4] Atreche, L. (2008) Pap Smears and Precancerous Lesions through Laboratory Experience of Pathological Anatomy of CHU HASSAN II of FES Concerning 2,359 Cases of FCV of 2004 to 2007. Thesis of Med, 2726.

[5] Pointreaua, Y., Ruffier Loubière, A., Denis, F. and Barillota, I. (2010) Cervical Cancer. Cancer/Radiotherapy, 14, S147-S153. https://doi.org/10.1016/S1278-3218(10)70018-4

[6] (2010) High Authority of Health. In: Recommendations in Public Health: Inventory and Recommendations for Cervical Cancer Screening in France. HAS, Paris, 1-256.

[7] Bernard, E., Saint-Lary, O., Haboubi, L. and Le Breton, J. (2013) Uterine Cancer Screening: Knowledge and Participation of Women. Santé Publique, 25, 255-262. https://www.cairn.info/revue-sante-publique-2013-3-page-255.htm

[8] Sancho-Garnier, H. (2005) Les problèmes de dépistage du cancer du col dans les différents pays. In: Le dépistage du cancer du col de l'utérus. Dépistage et cancer, Springer, Paris.

[9] Winer, R.L., Hughes, J.P., Feng, Q., O’Reilly, S., Kiviat, N.B., Holmes, K.K., et al. (2006) Condom Use and the Risk of Genital Human Papillomavirus Infection in Young Women. The New England Journal of Medicine, 354, 2645-2654. https://doi.org/10.1056/NEJMoa053284

[10] Boulanger, J.C., Sevestre, H., Bauville, E., Ghighi, C., Harlicot, J.P. and Gondry, J. (2004) Epidemiology of HPV Infection. Gynécologie Obstétrique \& Fertilité, 32, 218-223. https://doi.org/10.1016/j.gyobfe.2004.01.013

[11] Chee, C.C., Begassat, M. and Kovess, V. (2005) Factors Associated with Cervical Cancer Screening in a Mutualist Population. Revue d'Epidémiologie et de Santé Publique, 53, 69-75. https://doi.org/10.1016/S0398-7620(05)84573-0

[12] Edith, M. (2015) Benefit of Visual Inspection with Acetic Acid and Lugol Solute with Colposcope in Screening for Cervical Lesions in Gabon. Pan African Medical Journal, 22, 165.

[13] Bakali, G.K. (2012) Place of Visual Inspection with Acetic Acid in Cervical Cancer Screening at about 740 Cases at Souisse Maternity in Rabat. 